\title{
Effect of Food Patch Discovery on the Number of American Crows (Corvus brachyrhynchos) Using a Flight Lane
}

\author{
WILLIAM LANGLEY \\ Butler Community College, El Dorado, Kansas 67042 USA; email: blangley@butlercc.edu
}

Langley, William. 2014. Effect of food patch discovery on the number of American Crows (Corvus brachyrhynchos) using a flight lane. Canadian Field-Naturalist 128(2): 195-199.

In winter, American Crows (Corvus brachyrhynchos) move back and forth between night roosts and foraging sites along flight lanes. If communal roosts act as information centres, we would expect more birds to use a particular flight lane after discovery of a new food patch on that route. In this study, I investigated how the number of crows using different flight lanes was affected by the establishment of artificial food patches, as well as how crows responded to multiple days of provisioning and to the location of the food patch relative to the flight lane. After discovery of a food patch, the number of crows using the flight lane closest to it increased, while numbers using adjacent flight lanes remained the same or decreased, particularly when the patch was in the path of the flight lane and when food provisioning occurred for 2 consecutive days. These results support the idea that crows using winter roosts may make use of information on food availability obtained at the roost.

Key Words: American Crow; Corvus brachyrhynchos; flight lane; winter roost; food patch; communication

\section{Introduction}

During the winter, American Crows (Corvus brachyrhynchos) gather in night roosting groups consisting of thousands of birds (Kalmbach 1916; Haase 1963). They move to and from these night roosts in flight lanes: in the morning they radiate out to foraging areas and in the evening congregate at pre-roosting aggregation areas before flying to the night roost (Aldous 1944; Moore and Switzer 1998). In some cases, crows use the same flight lane regularly; in other cases, they change flight lanes (Aldous 1944; Stouffer and Caccamise 1991; Caccamise et al. 1997). Large increases in the number of crows using a flight lane have occurred, after a food patch such as grain spilled from a railcar or an un-harvested sunflower field, was discovered (Langley $1992 *)$.

An important potential function of a communal roost is that it can act as an information centre to facilitate finding and exploiting new food sources (Ward and Zahavi 1973; Weatherhead 1983). Common Ravens ( $C$. corax) and Hooded Crows (C. corone) that have discovered a food patch recruit others at the night roost to follow them to the food patch the next day (Marzluff et al. 1996; Sonerud et al. 2001). Crows can also learn by "local enhancement", i.e., by watching other individuals and responding if a food patch is discovered (Richner and Marclay 1991). The fact that tagged crows at a food patch do not stay together at the pre-aggregation site or roost raises the possibility that more fluid kinds of interactions may also occur among individuals at a large roost (Moore and Switzer 1998).

The information centre hypothesis predicts that, after discovery of a food patch on a flight lane, more birds would use that lane subsequently. In this study, I investigated how the number of crows using a flight lane is affected by the location of a provisioned food patch relative to the lane and the number of days over which it is provisioned. The approach was to present a food patch just after a snow storm when wheat plants (Tri- ticum aestivum) and un-harvested sorghum seed (Sorghum bicolor), the two main food items for crows during winter (Platt 1956), became less available.

\section{Study Area}

The study area was located in the northeast quadrant of the area surrounding a winter roost at Wichita, Kansas, where as many as 25000 birds a night have roosted over the past 50 years (Langley 1999). The area forms a rectangle of $969 \mathrm{~km}^{2}$ including northeastern Sedgwick County and the western edge of central Butler County (Figure 1). Land use consisted of agriculture (mainly wheat and sorghum fields), pasture, small farms, residences, and several small towns (Langley 1992*). Observations occurred from December to March, 19901998.

\section{Methods}

Food patches were set out before dawn on the morning after a snowfall of at least $8 \mathrm{~cm}$. A food patch consisted of $65 \mathrm{~kg}$ of corn kernels or bakery items. Food was spread over cleared frozen ground or on crusted snow and directly in the path of a flight lane and at least $10 \mathrm{~km}$ from the roosting site.

Three sometimes four flight lanes occurred in the study area. I selected three with the targeted lane having an adjacent lane on either side of it and identified the trajectory of each during preliminary observations. For one lane, I counted the number of birds by positioning myself so that birds flew overhead. To ensure that all the birds were counted, I took up a position that was located at the eastern edge of Wichita before dawn and counted until no birds passed overhead for 10 minutes. A different strategy was used to count the number of birds in the other flight lanes. First, I drove outward in a zig-zag pattern along the trajectory of the flight lane until no crows could be seen in flight or foraging in the fields for two $\left(2.56 \mathrm{~km}^{2}\right)$ sections (the roads border the edges of a square-mile section). Then, I retraced the 


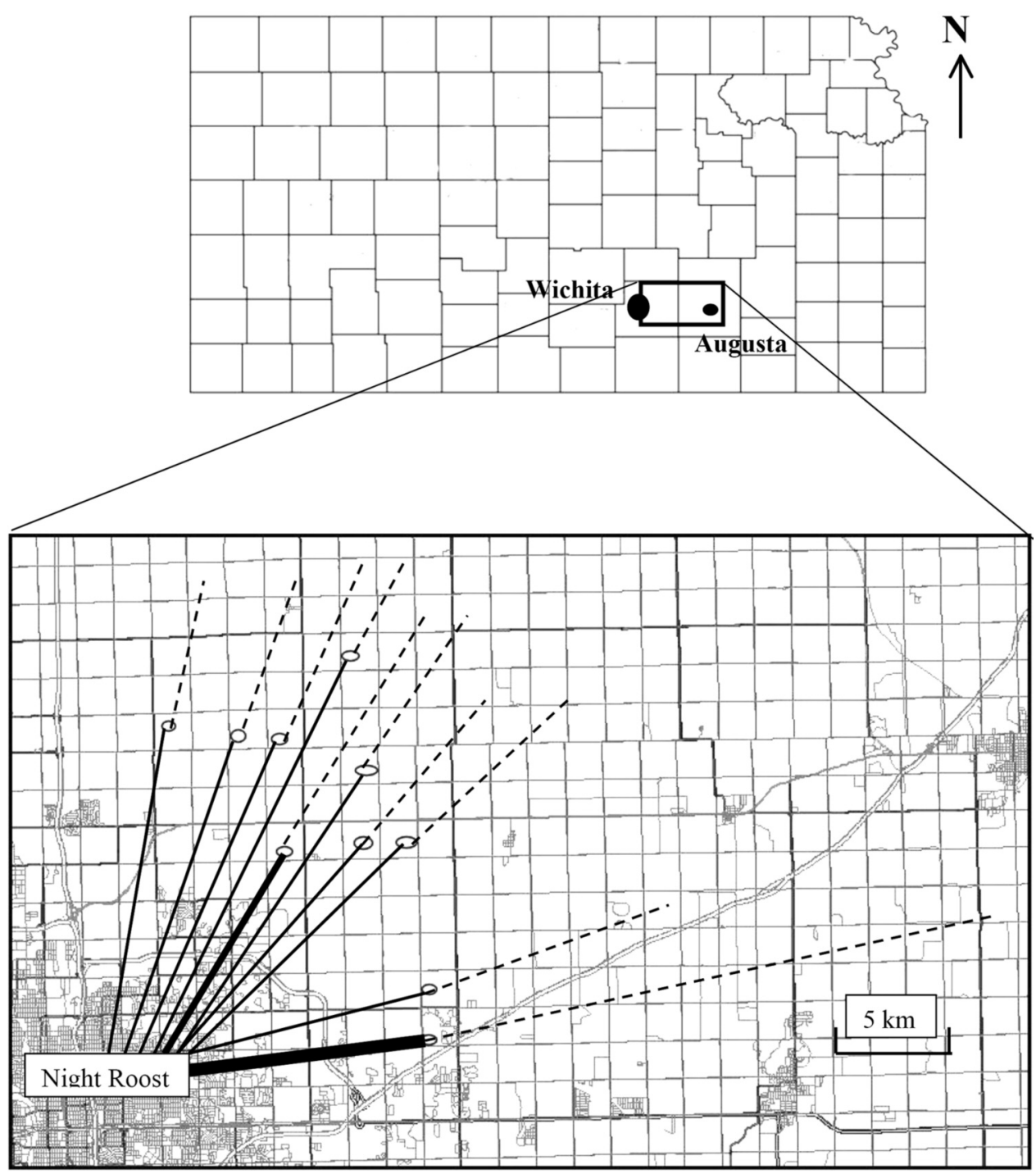

FIGURE 1. Northeast portion of Wichita, Kansas, showing night roosting site of American Crows (Corvus brachyrhynchos). Flight lanes (lines) and food patches (oval) are depicted for the first experiment. Thinnest lines show the targeted flight lane that was used in the study for only 1 year; a thicker line shows a lane used for 2 different years; and the thickest line shows a lane that was used for 4 different years. Dashed lines beyond the food patches show where some crows continued to fly and forage.

trajectory of that path counting all crows in the air or foraging. Counting early in the morning and following the trajectory out and back from the night roost reduced the possibility of missing any dispersing crows. Again, all crows were counted until none was observed for two sections. A similar process was repeated for a third flight lane. This counting procedure was conducted for three consecutive mornings before a forecasted snow event. Counting the number using a flight lane as they flew directly overhead had to be done first and was done this way for each flight lane on a different day so that counts were done in similar manner for all 3 flight lanes. The mean counts of those 3 days served as the baseline number of crows using those flight lanes.

On the morning after establishing a food patch, I counted the number of crows passing overhead from a position directly in line with the food patch and between it and the roost until no crows had arrived from the direction of the roost for 20 minutes. After that, I counted the number of crows using the adjacent 
flight lanes by tracing the trajectory from the roost and back as was carried out for counting before establishing a food patch. A survey of the crows at the food patch and beyond was conducted after all 3 flight lane counts were completed. These trials were conducted 14 times.

In a second experiment involving 8 trials, food patches were provisioned for 2 consecutive days rather than 1 day as in the first experiment. The change in the number of crows using that flight lane was measured on the third day. In a third experiment, a similar approach and counting procedures were used, but the food patches were offset from the flight lanes. They were placed at a distance of 1.0-1.5 km away from the targeted flight lane. These trials occurred 25 times.

Several non-parametric tests were used to compare differences (Siegel 1956): a Wilcoxon $T$ test was used to compare the number of crows using a flight lane before and after food provisioning; a Mann-Whitney $U$ test was used to compare the counts after 1 or 2 days of provisioning; and a $\chi^{2}$ test was used to compare the number of discovered food patches placed in or to the side of a flight lane.

\section{Results}

More crows used a flight lane after a food patch was set out for 1 day: pre-food, 152 (SD 220) and post-food, 588 (SD 597) (Wilcoxon test, $T=8, n=14, P<0.02$ ) (Figure 2). Although in two trials the number of crows using a flight lane decreased after the food patch was set out compared with number of crows using the flight lane beforehand, adverse weather (snow and fog) may have contributed to this decrease. The change in the number of crows using a flight lane ranged from -179 to 1992 . In three of these trials, crows were observed veering from an adjacent flight lane to the targeted flight lane. In these cases, the flight lanes merged into one that flew overhead at the counting location.

The number of crows using adjacent flight lanes declined from 1396 (SD 1134) to 1165 (SD 894) after the food patch was discovered (Figure 2), but the difference was not statistically significant (Wilcoxon test, $T=42, n=14, P=0.66)$. The response of crows in adjacent flight lanes veering and joining the targeted flight lane passing over the food patch contributed to the lower mean after the food patch was discovered.

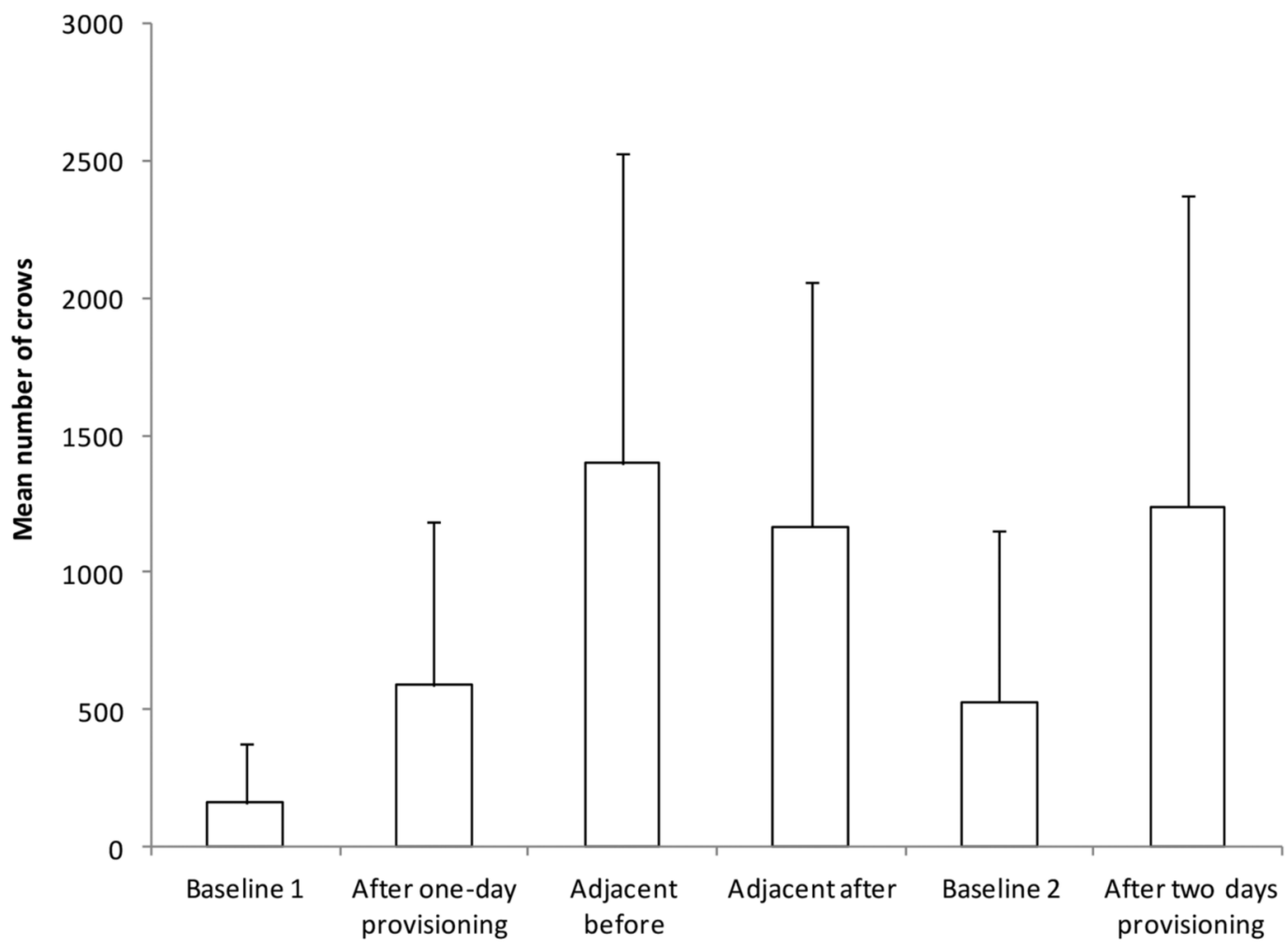

FIGURE 2. Mean number (and standard deviation) of American Crows (Corvus brachyrhynchos) in target lane before (baseline 1) and after 1 day of food provisioning, observed in adjacent lanes before and after food provisioning, and in the target lane before (baseline 2) and after 2 days of food provisioning. 
When food patches were provisioned for 2 days, the increase in number of crows using the target lane more than doubled from 528 (SD 625) to 1238 (SD 1140) (Wilcoxon test, $T=0, n=8, P<0.01$ ) (Figure 2). The number of crows using a flight lane after 2-day provisioning 1238 (SD 1140) was greater than the number after 1-day provisioning 588 (SD 597) (Mann-Whitney $U$ test, $\left.U=26, n_{1}=8, n_{2}=14, P=0.02\right)$.

When food patches were offset from the flight lane, different groups of crows discovered some of them. On three occasions, crows from the Wichita roost discovered the food patch as evidenced by the direction from which the birds arrived (trajectory from roost), by their early arrival (0800), and by the increase in the number of birds in these three flight lanes from prefood 178 (SD 158) to post-food 291 (SD 131). These counts were carried out as in prior experiments. Seven other food patches were found by crows not from the Wichita roost. These crows arrived from a different direction than those from the Wichita roost, at later time (1000) and in fewer numbers (1-10 birds). No other crows were observed in the surrounding area. Of the 25 food patches set to the side of the path of flight lane, 15 were not discovered by any crows the day after provisioning. The proportion of food patches discovered by crows from the Wichita roost when they were placed on the flight lane (12/14) was significantly greater than when they were offset from the flight lane (3/25) $\left(\chi^{2}=17.6, P<0.001\right)$.

\section{Discussion}

The increase in the number of crows using flight lanes where supplementary food had been placed the previous day suggests that information obtained at the roost enabled crows to adjust their foraging behaviour to take advantage of the new food supply. This was especially true when the new food patches occurred in the path of the flight lane and were provisioned for more than 1 day. These data support the hypothesis that night roosts can act as information centres. In this study, the roost was large ( $>25000$ crows) and the number of additional individuals using a flight lane exceeded 1000 on five occasions.

However, the response to discovery of food patch was highly variable, suggesting that additional factors may have influenced the number of crows using a particular flight lane. When a large number of crows responded to the discovery of a food patch, there were too many to access or use the food. Furthermore, most of these crows flew past the food patch, sometimes more than $10 \mathrm{~km}$, suggesting that some were foraging in areas other than the food patch. Although the discovery of a food patch proved to be an attraction, not all arriving individuals necessarily made use of it.

Presumably, the use of flight lanes can be beneficial to crows in more ways than enhancing the discovery of food sources. Vigilance is important while foraging, and flocks can provide an optimal tradeoff between feeding and watching for danger (Ward and Low 1997). When competing for a carcass with a larger raptor, aggregation in flocks ensures success more often for the crows. For example, a flock of American Crows was more successful in displacing a Red-tailed Hawk (Buteo jamaicensis) from an animal carcass than a few individuals (Langley 2001).

During this study, crows occurred in three kinds of associations. The most abundant were those in flocks from the Wichita roost. Less common were groups of 2-6 birds that presumably represented territorial family groups not associated with the roost (Knopf and Knopf 1983). A third type observed rarely and intermittently, ranged in size from 10-100 individuals, possibly representing non-breeding crows in the area. Groups of non-breeding crows have been observed near urban areas in California (Caffrey 1992).

\section{Acknowledgements}

I wish to thank Alan Maccarone for reviewing the manuscript and the Chickadee Check-off of the Kansas Department of Wildlife for financial support at the start of the project.

\section{Documents Cited (marked * in text)}

Langley, W. M. 1992. Foraging behavior in winter roosting crows in Wichita area. Non-game report. Kansas Department of Wildlife and Parks, Pratt, Kansas. 55 pages.

\section{Literature Cited}

Aldous, S. E. 1944. Winter habits of crows in Oklahoma. Journal of Wildlife Management 8: 290-295.

Caccamise, D. F., L. M. Reed, J. Romanowski, and P. C. Stouffer. 1997. Roosting behavior and group territoriality in American crows. Auk 114: 628-637.

Caffrey, C. 1992. Female biased delayed dispersal and helping in American Crows. Auk 109: 609-619.

Haase, B. L. 1963. The winter flocking of the common crow (Corvus brachyrhynchos Brehm). Ohio Journal of Science 63: 145-151.

Kalmbach. E. R. 1916. Winter crow roosts. U. S. Department of Agriculture Yearbook 1915: 83-100.

Knopf, F. L., and B. A. Knopf. 1983. Flocking patterns in foraging American Crows in Oklahoma. Wilson Bulletin 95: 153-155.

Langley, W. M. 1999. Changes in crow populations in Kansas. Kansas Ornithological Society Bulletin 50: 35-38.

Langley, W. M. 2001. Crow and red-tailed hawk interaction at animal carcasses. Transactions Academy of Science Kansas 104: 28-30.

Marzluff, J. M., B. Heinrich, and C. S. Marzluff. 1996 Raven roosts are mobile information centres. Animal Behaviour 51: 89-103.

Moore, J. E., and P. V. Switzer. 1998. Preroosting aggregations in the American crow, Corvus brachyrhynchos. Canadian Journal of Zoology 76: 508-512.

Platt, D. 1956. Food of the crow, Corvus brachyrhynchos Brehm, in south-central Kansas. University of Kansas Publications Museum Natural History 8: 477-498.

Richner, H., and C. Marclay. 1991. Evolution of avian roosting behavior: a test of the information centre hypothesis 
and of a critical assumption. Animal Behaviour 41: 433438.

Siegel, S. 1956. Non-parametric Statistics: for the Behavioral Sciences. Maple Press, York, Pennsylvania, 312 pages.

Sonerud, G. A., C. A. Smedshaug, and O. Brathen. 2001 Ignorant hooded crows follow knowledgeable roost-mates to food: support for the information centre hypothesis. Proceedings of Royal Society London B 268: 827-831.

Stouffer, P. C., and D. F. Caccamise. 1991. Roosting and diurnal movements of radio-tagged American crows. Wilson Bulletin 103: 387-400.
Ward, C., and B. S. Low. 1997. Predictors of vigilance for American crows foraging in an urban environment. Wilson Bulletin 109: 481-489.

Ward, P., and A. Zahavi. 1973. The importance of certain assemblages of birds as "information centres" for foodfinding. Ibis 115: 517-534.

Weatherhead, P. J. 1983. Two principal strategies in avian communal roosts. American Naturalist 121: 237-243.

Received 15 November 2013

Accepted 28 January 2014 